\title{
Aspira Indwelling Catheter
}

National Cancer Institute

\section{Source}

National Cancer Institute. Aspira Indwelling Catheter. NCI Thesaurus. Code C157269.

A proprietary indwelling catheter used to drain accumulated fluid from the pleural or peritoneal cavity to relieve symptoms associated with malignant pleural effusion or malignant ascites. The Aspira system connects to a low-vacuum siphon pump that drains into a bag. 